Prepared for the U.S. Department of Energy

under Contract DE-AC05-76RL01830

\title{
Summary of FY13 Industry Interviews
}

G Hund

AM Seward

NH Gunawardena
AJ Kurzrok

ET Wyse

September 2013

Pacific Northwest

NATIONAL LABORATORY

Proudly Operated by Battelle Since 1965 


\title{
DISCLAIMER
}

This report was prepared as an account of work sponsored by an agency of the United States Government. Neither the United States Government nor any agency thereof, nor Battelle Memorial Institute, nor any of their employees, makes any warranty, express or implied, or assumes any legal liability or responsibility for the accuracy, completeness, or usefulness of any information, apparatus, product, or process disclosed, or represents that its use would not infringe privately owned rights. Reference herein to any specific commercial product, process, or service by trade name, trademark, manufacturer, or otherwise does not necessarily constitute or imply its endorsement, recommendation, or favoring by the United States Government or any agency thereof, or Battelle Memorial Institute. The views and opinions of authors expressed herein do not necessarily state or reflect those of the United States Government or any agency thereof.

\author{
PACIFIC NORTHWEST NATIONAL LABORATORY \\ operated by \\ BATTELLE \\ for the \\ UNITED STATES DEPARTMENT OF ENERGY \\ under Contract DE-AC05-76RL01830
}

Printed in the United States of America

Available to DOE and DOE contractors from the

Office of Scientific and Technical Information,

P.O. Box 62, Oak Ridge, TN 37831-0062;

ph: (865) 576-8401

fax: $(865) 576-5728$

email: reports@adonis.osti.gov

Available to the public from the National Technical Information Service

5301 Shawnee Rd., Alexandria, VA 22312

ph: (800) 553-NTIS (6847)

email: orders $a$ ntis.gov <http://www.ntis.gov/about/form.aspx>

Online ordering: http://www.ntis.gov

This document was printed on recycled paper. 


\title{
Summary of FY13 Industry Interviews
}

\author{
G Hund \\ AJ Kurzrok \\ AM Seward \\ ET Wyse \\ NH Gunawardena
}

September 2013

Prepared for

the U.S. Department of Energy

under Contract DE-AC05-76RL01830

Pacific Northwest National Laboratory

Richland, Washington 99352 


\section{Background}

The spread of weapons of mass destruction relies on the illicit procurement of dual-use items, and industry plays a critical role in preventing these transfers. Export control systems regulate industry's sales, but there additional steps that industry and government can take to stop proliferators. Collectively, these additional steps are known as industry self-regulation.

The industry self-regulation project at PNNL has identified several approaches to going "beyond compliance” in recent years, including corporate sustainability, competitive advantages for nonproliferation, and a third party. In FY12 the project team moved from a research phase to an implementation phase, and prepared to seek feedback from industry on these topics. This effort included research to identify American manufacturers of Nuclear Suppliers Group (NSG) Part 2 Annex commodities.

To gain initial responses from industry about whether these ideas could be reasonably implemented, in FY13 the project team conducted a series of outreach interviews. Outreach was initially focused on firms in the carbon fiber, filament winding, and maraging steel sectors. The project team chose these sectors based on the number of firms that produce these items and their proliferation relevance. As the year progressed, the team widened its outreach to manufacturers of a variety of NSG-controlled commodities.

In total, the project team contacted 57 firms and conducted 13 interviews. The interviewed firms manufactured or distributed at least 11 controlled commodities ${ }^{1}$. All interviews were conducted on a notfor-public-attribution basis, and all information in this summary, unless otherwise cited, can be assumed to be derived from the interviews.

Interviews focused on the three primary areas of research for the industry self-regulation project: sustainability, competitive advantage, and a third party for nonproliferation. The project's interview protocol is included as Appendix A.

\footnotetext{
${ }^{1}$ Some firms manufacture or distribute more than one type of controlled commodity.
} 


\section{Contents}

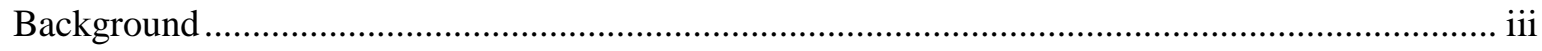

1.0 Interviewee Responses to PNNL Research Topics .............................................................

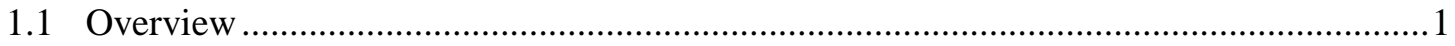

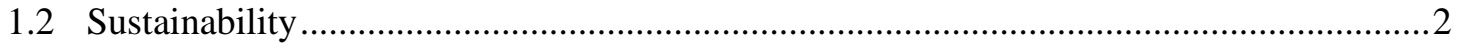

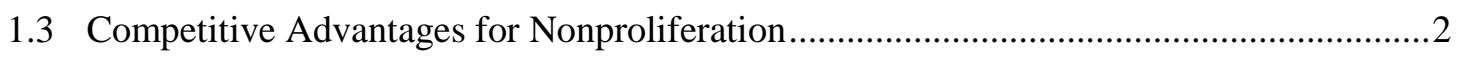

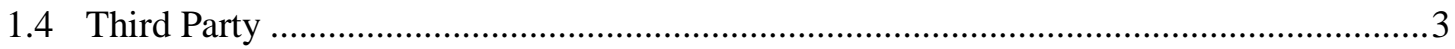

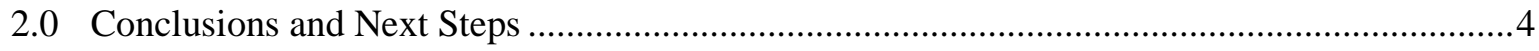

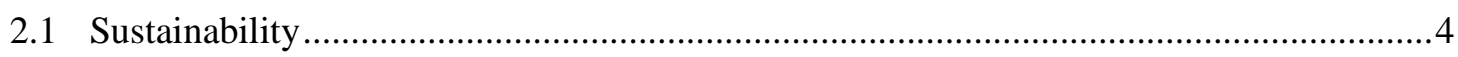

2.2 Competitive Advantages for Nonproliferation.............................................................

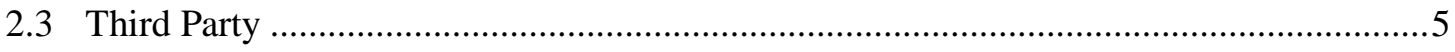

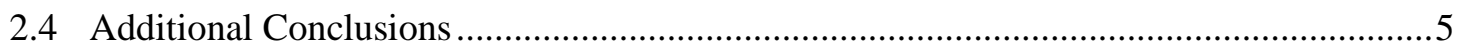

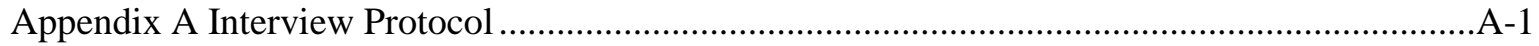

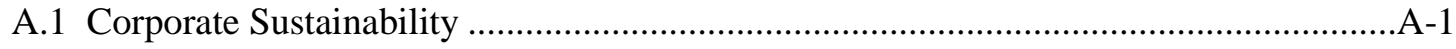

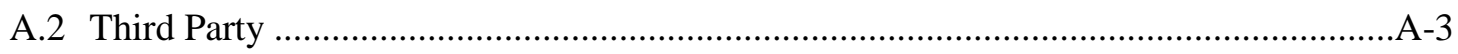

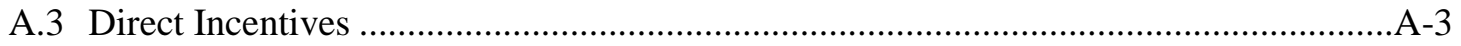

Appendix B: Industry Perspectives on Additional Topics............................................................ B-1

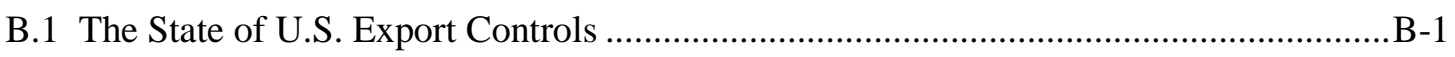

B.2 Internal Compliance Programs.................................................................................... 


\subsection{Interviewee Responses to PNNL Research Topics}

\subsection{Overview}

The 13 interviews did not yield a consensus opinion on any PNNL research topic. Interviewees ranged from highly supportive to hostile, and some interviewees were quite positive about some topics while remaining quite negative about others. In addition to feedback about the three areas of PNNL research, interviewees frequently volunteered their opinions on competition within their market sector, their firms' internal compliance programs, and the state of U.S. export controls. Perhaps unsurprisingly, the wider context of interviewee perspectives on internal governance and regulation often appeared to define their openness to one or more self-regulation approach. A summary of industry perspectives on U.S. export controls and internal compliance programs is included in Appendix B.

The sections below summarize the interviewee feedback by PNNL research topic. Though the project team provided all interviewees with similar background material, each interviewee did not discuss every topic because of the semi-structured nature of the conversations ${ }^{2}$.

Figure 1 provides an overview of interviewees' sentiment towards PNNL research topics. Green boxes represent strong support, yellow represents some concerns, and red represents strong disagreement. This color-coding scheme is necessarily an abstraction of each interviewee's response, and additional details are provided in the text for each theme that follows.

\begin{tabular}{|c|c|c|c|}
\hline \multirow[b]{2}{*}{ Industry } & \multicolumn{3}{|c|}{ PNNL Research Topics } \\
\hline & Sustainability & $\begin{array}{l}\text { Competitive } \\
\text { Advantage }\end{array}$ & Third Party \\
\hline \multicolumn{4}{|l|}{ Carbon Fiber (Two interviewees) } \\
\hline \multicolumn{4}{|l|}{ Crucibles } \\
\hline \multicolumn{4}{|l|}{ Electronic Systems } \\
\hline \multicolumn{4}{|l|}{$\begin{array}{l}\text { Filament Winding Machines (Two } \\
\text { interviewees) }\end{array}$} \\
\hline \multicolumn{4}{|l|}{ Frequency Changers } \\
\hline \multicolumn{4}{|l|}{ Maraging Steel (Two interviewees) } \\
\hline \multicolumn{4}{|l|}{ Mechanical Rotating Mirror Cameras } \\
\hline \multicolumn{4}{|l|}{ Pressure Transducers } \\
\hline \multicolumn{4}{|l|}{ Spin and Flow-Forming Machines } \\
\hline \multicolumn{4}{|l|}{ Triggered Spark Gaps } \\
\hline Vacuum Pumps & & & \\
\hline
\end{tabular}

Figure 1: Interviewee sentiments toward PNNL research topics

\footnotetext{
${ }^{2}$ The project team revised the background materials provided to interviewees for clarity during the interview campaign, but the text did not change substantively.
} 


\subsection{Sustainability}

Several interviewees said that integrating nonproliferation into corporate sustainability could be valuable. One noted that companies have their own culture, and a pledge could rally employees. However, the interviewee was less sanguine about metrics, and noted that the firm's recent participation in an emissions survey that was not useful. Another interviewee also thought that promoting nonproliferation as sustainability was valuable to raise awareness because "we all want to make money, but at what cost?”

Some had negative experiences with other voluntary initiatives, and feared what the impacts of nonproliferation for sustainability would be. One said that voluntary initiatives can become mandatory over time, and described the history of the steel industry. Forty years ago the supply chain was based on the integrity of each supply chain partner. Then, the mills developed standards. ISO standards followed that, and AS9100 includes standards specific to the aerospace industry. The interviewee noted that Nadcap (Formerly the National Aerospace and Defense Contractors Accreditation Program) began with the heat treaters and platers, and the additional requirements doubled the size of their quality control departments. Further, Nadcap operates as a monopoly, so firms are forced to pay whatever rates Nadcap sets because it is not worth losing accreditation from the major aerospace manufacturers. Despite these frustrations, it is still beneficial for the aerospace industry to be able to define its own set of metrics in standards such as AS9100, subject to government approval. Similarly, other individuals stated that ISO standards were not worth the time and that ISO auditors were expensive.

Some interviewees did not see much value in a sustainability approach. One questioned the premise of PNNL's sustainability approach because examples of other self-regulatory schemes such as the Kimberley Process were incongruent. Diamonds are consumer items, but consumers do not care about dual-use commodities. One was generally reluctant about things that are voluntary because it "opens you up to getting hit up for everything.”

The role of investors was often a critical point for interviewees when considering sustainability, but their perspectives varied. One interviewee said that including investors was the most compelling element of a code of conduct. Others, however, believed that only an extremely savvy investor would consider export compliance, and one believed that nonproliferation would be a "footnote issue" to investors. Another interviewee said that customers care about a "Made in the USA" reputation (and the related protection of U.S. intangible technology), but insurers and stockholders less so.

\subsection{Competitive Advantages for Nonproliferation}

Numerous interviewees responded positively to the prospect of competitive advantages for nonproliferation. The most commonly cited advantage was tax breaks for compliance investments such as software and training, which nearly everyone said would be welcome.

One interviewee thought that it would be useful to have a certification to show to customers. The individual's firm does business with all of the "big name" companies, which regularly ask for evidence of compliance. A certificate "would go a long way." The individual noted that supplier certification is a growing trend, especially for companies that have gotten into trouble in the past. 
Another firm's goal is to avoid press releases and fines, and found it valuable to buy goodwill with enforcement agencies. The interviewee cooperates with many agencies, and thought it would be valuable if the government had an interagency policy on getting "credit" for support across the interagency in penalty mitigation determinations. A verified exporters list that gives a yes/no answer within two weeks would help, and the firm "dreamed" of a single export agency, rather than working with several U.S. government agencies.

One interviewee believed that a B2B network could be worthwhile, but thought that a "Good Housekeeping" seal would have perverse effects because it would "paint a target" on the company. Furthermore, the interviewee was skeptical of preferred status with CBP, noting that this would be similar to other CBP guarantees and did not believe that CBP could actually deliver. Others also researched CTPAT, but the benefits did not outweigh the costs for their firms.

However, another individual said that C-TPAT might be a useful tool because it could provide assurances about the security of imports to the United States as well as the security of items that it will receive via export. This is particularly critical in at least one country, where mega-firms that own some of this company's clients also own elements of the national nuclear program. The customers must assure the company that they will not transfer the items to a nuclear end use. The company undertakes a proactive approach and sends a letter alerting the end user to the export control restrictions on the products, even for EAR99 products that are generally unrestricted.

One interviewee noted that the phrase "preferential treatment" carries a negative connotation in that firm's industry. There was recently a lawsuit in the industry about preferential treatment, so firms are wary of any activity that could give the appearance of some firms receiving preferential treatment.

\subsection{Third Party}

Many of the interviewees believed that a third party for nonproliferation would be a useful development. One thought it "made sense," and another said that the firm would be willing to share data with other firms if there was a clearing house. This firm currently maintains an internal database of "red flag” companies. An interviewee said that a third party would be "wonderful” because illicit buyers come with many names, and that a third party would cut down on research time.

One individual, speaking in favor of information sharing, said that BIS staff are very good at what they do, but they are spread too thin. Firms that just do the required screening do not see the whole picture. There are many entities that are working hard to hide that they are the bad guys. Furthermore, sales are driven by a sales force, but leads come to a company in many ways. The sales force may not know with whom they are dealing. For example, many leads come through distributors or the web. The internet could support information-sharing, particularly through a "Wikipedia"-like website.

Some interviewees recognized that there could be hurdles to implementation. Two suggested that corporate attorneys would need to do a legal analysis. One noted that the other manufacturers of that firm's products may not support a third party. 
Other interviewees did not believe that a third party would be valuable. One was not interested in helping competitors, and found it hard to see the industry banding together. Another did not think a third party would be useful because it sounded like NSG denial sharing. The firm was more comfortable with government agencies and did not want to share with firms. When there is something problematic this individual thought it was far better to go into BIS for a license. The individual also questioned the intelligence value of suspicious inquiries a priori and asked how one would characterize a "suspicious request”, noting that the EAR's standard for knowledge was to comply in good faith through standard business practices. The EAR cannot stop theft and customers from lying.

Others did not find a third party compelling and said that it sounds like another layer of government intervention. One added that the enforcement of laws is a U.S. Government responsibility, and added that a third party might make sense for a big firm, but not for a firm that deals with a smaller number of ECCNs.

\subsection{Conclusions and Next Steps}

The FY13 interview campaign greatly informed the next steps for the industry self-regulation project. None of the PNNL research themes enjoyed clear consensus support, but interviewees also did not universally dismiss any theme.

One important methodological note is that the FY13 interview campaign primarily reached out to individuals with export control responsibilities at a firm. It may be valuable to consider how corporate executives would view these research themes. Executives may find greater value in some topics, such as sustainability, compared to working-level staff.

\subsection{Sustainability}

For many interviewees, interest in sustainability was contingent upon subsequent preferential treatment by investors. An active demand for nonproliferation data from investors (or, possibly, from large supply chain partners) appears to be necessary to compel firms to action.

Next Step: Further work on nonproliferation as a corporate sustainability value should focus on gaining the interest of the sustainable investment community.

\subsection{Competitive Advantages for Nonproliferation}

Competitive advantages for nonproliferation were the most favorably-considered element of PNNL's research. As noted in the March 2013 white paper on competitive advantages, it will be important to identify an appropriate partnership scenario between industry and government that could take advantage of desired competitive advantages as an incentive for participation.

Within this context, more discussion is necessary on tax write-offs. While nearly all interviewees saw tax write-offs positively, other organizations, such as industry associations, may be best positioned to promote this concept. 
Furthermore, the concept of a "Good Housekeeping” certification requires further definition; particularly who, specifically, would be the certification authority and what benefits would a company receive for certifying. The answers to these questions may be largely for industry to decide.

Next Step: Discuss industry-government partnership scenarios that could use competitive advantages as incentives.

\subsection{Third Party}

There appears to be sufficient interest to merit further activities on developing a third party for nonproliferation. Many firms would be interested in up-to-the-minute information about proliferation trends and potentially suspicious buyers.

Many firms, but not all, have outreach contacts with federal law enforcement, and there is inconsistent reporting of suspicious inquiries. The existence of cooperation with law enforcement does not necessarily undercut the rationale for a third party because interviews suggest that U.S. agencies are not currently is not providing information the type of proliferation trend data that a third party may.

Next Step: Recognizing that the effectiveness of a third party grows with the number of participants, PNNL should identify the proper implementation partners for a third party. It may also be critical to engage with U.S. federal agencies with a potential interest in a third party to understand their perspectives on implementation.

\subsection{Additional Conclusions}

Several additional conclusions emerged from interviewee comments on U.S. export controls, internal compliance programs, and sales practices and market competition:

- Corporate culture matters. Some firms responded to export enforcement actions by changing processes and becoming nonproliferation leaders, while others became recalcitrant. There may be value in mechanisms that can allow analysts and law enforcement to clearly distinguish between these types of firms and prioritize their investigations accordingly.

- Similarly, many companies are proud of the national security role that they play, and this is an advantage even if it does not improve profitability—nonproliferation is the "right thing to do".

- Proliferation procurement strategies via brokering can be countered. Some firms have ICPs that could serve as models for the private sector as a whole.

- There is a spectrum of competitiveness across industry, and perceptions of competition appeared in part to drive interviewees' openness to self-regulation approaches. One question for further activities is whether a private sector "coalition of the willing" is sufficient, or whether an implementation would only be effective with all firms participating. There may be value in redoubling outreach efforts to industry associations. 



\section{Appendix A Interview Protocol}

For several years, our team has studied the role of industry in securing and controlling the goods and services along its supply chain that could be diverted and used in a nuclear weapon, what we term nuclear nonproliferation. We focus on the concept of industry self-regulation, recognizing the critical role that industry can play in working with government to prevent proliferation. There is growing awareness among government, academia, NGOs and industry itself that industry's role is critically important and we are interested in identifying how to best leverage industry's knowledge and responsibility to this end. We have conducted reviews of the legal issues surrounding the self-regulation concept, held a series of interviews with industry representatives, and published and presented our analysis in numerous forums, including the Nuclear Suppliers Group, Missile Technology Control Regime, and Wilton Park in England.

We also convened an Industry Engagement Workshop last fall that brought together representatives from the private sector, academia, NGOs and government to discuss the self-regulation concept. It was a great meeting, with a lot of enthusiasm from the participants, and a lot of forward thinking. Over the past year we have developed these ideas into several publications.

Our goal now is to get input on these ideas from a wide array of industry partners. There are at least three areas we would like to talk about today: corporate sustainability, a nonproliferation third party for dual-use industries, and direct incentives for participation. We would also welcome your thoughts on other areas for cooperation between government and industry.

You may have worked with export control enforcement agencies such as the Bureau of Industry and Security or ICE/Homeland Security Investigations. Pacific Northwest National Laboratory is operated by the Battelle Memorial Institute on behalf of the Department of Energy. We are not an export control enforcement agency. Today's conversation will be used exclusively to support our ongoing research for DOE about industry engagement.

- Tell us about your company’s export control program?

- Before we get into the substance of the ideas, do you have any questions?

\section{A.1 Corporate Sustainability}

As you know, instead of seeking commodities with explicitly nuclear applications, proliferators are increasingly purchasing dual-use commodities. As the gatekeeper of international manufacturing, shipping, and banking, the private sector is often described as "the first line of defense" against the spread of weapons of mass destruction (WMD) capabilities.

Despite this exposure, one of the things we hear is that when we talk about "nonproliferation," industry says that's a job for government, but if you ask about "controlling the goods and services throughout the supply chain,” everyone agrees that is a crucial job for industry. 
An alternative approach to engaging industry on nonproliferation would be to weave it into an existing framework that firms use to monitor impacts: "corporate sustainability." Corporate sustainability is an umbrella term that subsumes several ideas, including: corporate social responsibility, business ethics, stewardship, corporate citizenship, and the triple bottom line.

Unlike government-led initiatives, corporate sustainability is the private sector's own approach to managing the social, environmental, and economic impacts of its operations. By taking a longer-term perspective that includes the full spectrum of potential stakeholders, boardrooms of companies pursuing sustainable operations go beyond simple regulatory compliance to better assess the full spectrum of impacts from their decisions.

The corporate sustainability approach works because of an infrastructure of transparency standards that monitors performance and a network of investors that apply their market power to incentivize positive behavior. Nonproliferation could be added to this framework, and market mechanisms could reward those who go beyond compliance.

We think the first step towards integrating nonproliferation into the corporate sustainability framework is a Nonproliferation Pledge. Such a pledge, signed by the CEO, would send a strong message that a firm is aware of its nonproliferation responsibilities and committed to protecting the goods and services throughout its supply chain. Many industries use similar pledges to communicate commitment.

Beyond adherence to a pledge, firms could publish data about performance indicators that stakeholders could use to evaluate which firms had superior performance. Many firms already release this sort of data for issues such as environmental management, respect for human rights, and fair labor practices. We have developed several sample indicators, which we would be happy to talk about in more depth.

Questions:

- What is your reaction to broadening the term corporate sustainability to include these themes around nonproliferation? How would it be viewed by companies, such as those in your industry?

- How important would it be for you to be able to differentiate yourself from competitors on questions of compliance and sustainability?

- How important would it be for stakeholders such as investors (or banks that might make trade loans) to value or offer preferential treatment based on a commitment to nonproliferation?

- What is your reaction to the idea of a company signing a pledge? Would it be a useful differentiator?

- Similarly, what is your reaction to the idea of using performance indicator reporting to demonstrate your commitment? 


\section{A.2 Third Party}

We have also been researching the concept of an independent, industry-led organization ("third party”) to enable member companies to more effectively support nonproliferation. Such a third party comprised of members of one or more dual-use industries - could serve as a mechanism for information collection and sharing among companies and with government authorities, as well as for the development and promotion of a set of nonproliferation best practices.

The information gathered by a company during its export control compliance activities is not typically shared among competitors or, unless required, with government authorities. Yet companies receive and often deny suspicious requests. By sharing denial data that would have otherwise ended up in the garbage bin, the dual-use industry could collectively raise its defenses to proliferation by alerting companies of the potential for illicit export requests involving prohibited end users, end uses, or destinations. Such information sharing could also help companies comply with export control regulations, and thereby avoid the consequences of regulatory violations, such as enforcement action and a damaged reputation.

The third party could also serve to develop and promote a set of nonproliferation best practices for industry members. Best practices could focus on the companies' internal compliance systems for dual-use export control, including procedures and practices for reviewing export requests.

We have broached this concept with a number of audiences, including industry, and it has been received with interest. As potential members have indicated that legal issues are an important concern, we conducted an analysis of the legal issues involved in creating such a third party. Our analysis concluded that legal issues would in fact be manageable, and that it would be up to industry to determine the specific structure and function of a nonproliferation third party to best suit their needs and interests.

Questions:

- What is your reaction to this concept of a nonproliferation third party?

- Follow up questions about the potential operation of a third party (may be sensitive):

o What is the usual protocol when you receive a suspicious export request?

o What protocol, if any, do you currently use to share export information with other companies even if it is informal? Are there any trade organizations where companies in your industry meet and discuss such issues? If so, do you participate?

- What challenges do you see in creating such an organization?

\section{A.3 Direct Incentives}

Government has many potential tools to incentivize self-regulation in areas of interest to business, including tax credits and licensing and export policies. 
One possible incentive is a tax credit that encourages investment in compliance infrastructure. The U.S. Government already uses tax incentives to promote socially-beneficial behavior, for example energy efficient appliances, home buying, and retirement savings. To promote nonproliferation and support companies seeking to export their products, government could institute tax credits for activities such as trainings and the purchase of compliance software packages.

Government could also extend preferential export and licensing policies to exporters who commit to certain compliance criteria and allow verification of such measures. Saved time and increased predictability create value for exporting companies trying to coordinate shipment and payment logistics, and government has tremendous influence on both. The Customs-Trade Partnership Against Terrorism (C-TPAT) has used this strategy in attempt to enhance security of imports entering the United States. Customs and Border Protection (CBP) rewards importers' increased commitment to and verification of security measures with access to faster lanes and procedures, less frequent inspections, and front-of-theline privileges for inspections.

These could include:

- Government has many potential tools to incentivize self-regulation in areas of interest to business, including tax credits and licensing and export policies.

- One possible incentive is a tax credit that encourages investment in compliance infrastructure. The U.S. Government already uses tax incentives to promote socially-beneficial behavior, for example energy efficient appliances, home buying, and retirement savings. To promote nonproliferation and support companies seeking to export their products, government could institute tax credits for activities such as trainings and the purchase of compliance software packages.

- Government could also extend preferential export and licensing policies to exporters who commit to certain compliance criteria and allow verification of such measures. Saved time and increased predictability create value for exporting companies trying to coordinate shipment and payment logistics, and government has tremendous influence on both. The Customs-Trade Partnership Against Terrorism (C-TPAT) has used this strategy in attempt to enhance security of imports entering the United States. Customs and Border Protection (CBP) rewards importers' increased commitment to and verification of security measures with access to faster lanes and procedures, less frequent inspections, and front-of-the-line privileges for inspections.

Questions:

- How would these incentives be viewed by your management?

- Which ones, if any, would support your operations?

- Do you see any other areas that could serve as incentives?

Follow up questions:

- Are there any areas that we could give you more information on? Do you have any other questions for us? 
- Our goal is not just to research these ideas, but to try to develop a set of partners that will help us bring them to fruition. Which of these ideas could you envision your company supporting?

- [If positive reaction] What do you see as the appropriate next step? 



\section{Appendix B: Industry Perspectives on Additional Topics}

\section{B.1 The State of U.S. Export Controls}

Opinions ranged widely about export control in the United States. Several firms had experienced enforcement actions that changed their approach to export control, some positively and others negatively.

Upon being hired, one interviewee filed a voluntary self-disclosure for the company's "sins of the past”, and since then has strengthened the firm's approach to compliance. However, the deterrent to noncompliance is weak. The firm spends $\$ 250,000 /$ year on export control, but TW Metals' recent $\$ 500,000$ fine for transshipment through Canada was an example of insignificant penalties. TW Metals was doing exactly what the government warns against doing — 45 shipments through Canada to China and Israel in blatant violation of export laws ${ }^{3}$. The interviewee said that the fines for such cases should be much higher. With the penalties so low, some firms may look at the cost/benefit ratio and roll the dice. This firm, he noted, will still keep its compliance program regardless.

The FBI raided one interviewee's firm several years ago, and since the incident the firm has put many checks and balances in place. An interviewee said that the firm is "more aware" and takes "more steps than most people do.” However, the interviewee expressed frustration with BIS' decision to turn down licenses when it knew that the customer would simply purchase somewhere else. The interviewee thought that a more effective route would be to allow the sale and follow up with post-shipment verifications. That course of action "lets us keep an eye on it.” The interviewee was particularly displeased by one recent case in particular where the firm was denied a U.S. export license, which resulted in the loss of a $\$ 200 \mathrm{~K}$ order. The order will be filled by another country with no ability for U.S. agents to conduct any post-shipment verification.

One interviewee is not interested in participating in the export control process and expressed frustration and anger with the export control system, asking "How am I supposed to know this?" and "How are we supposed to keep up?” The interviewee does not know what a suspicious inquiry would look like and does not know what the end user does with the firm's product. The interviewee is not willing to go to an export control workshop, nor willing to send others from the firm to one.

Another interviewee expressed extreme unhappiness with the export control system, particularly enforcement. The interviewee said that BIS's Office of Export Enforcement and State's Directorate of Defense Trade Controls are "only looking for the big guys" such as this firm, and noted filing tips several times with BIS about potential violations but "nobody cares because they [the accused firm] are too small.” The interviewee's firm "went through a DOJ investigation years ago," that, in the interviewee's words, yielded nothing, but almost put the company out of business because they had difficulty acquiring export licenses while they were under investigation. The interviewee did not believe that industry selfregulation offered any benefits to industry, and insisted that the primary issue in export control is government implementation.

\footnotetext{
3 “Order relating to TW Metals, Inc.” U.S. Department of Commerce, Bureau of Industry and Security, March 11, 2011, http://beta-efoia.bis.doc.gov/index.php/component/docman/doc_view/593-e2201?Itemid=.
} 
An interviewee was concerned by recent changes that mean there is no longer an ECCN for filament winding software, which opens the door to many risks.

\section{B.2 Internal Compliance Programs}

Approaches to handling suspicious inquiries varied among the interviewees. One firm will send any suspicious orders to a BIS field office. Another will still file an export application, despite suspicions, but will call BIS immediately to pass along the concerns. One interviewee's firm is never afraid to tell the government about suspicious requests, though it may do so through outside counsel.

When a member of one interviewee's sales team finds a request that is "funny," he or she forwards it to the interviewee, who uses the Visual Compliance software package to do further research. The firm has a number of red flag indicators, including the use of Gmail accounts. If unable to resolve the suspicion, the interviewee will push the information forward to law enforcement.

The interviewee will share information about suspicious inquiries across the company. Often, corporate service centers will receive identical requests within hours of each other, and the interviewee can keep sales staff aware of new risks. However, the interviewee had no interest in helpings competitors avoid fines, noting that "it is not my job to make it easier for them." Sometimes the interviewee will have very careful conversations with his competitors about best practices for compliance systems, but these are guarded when they do occur.

Another individual has an FBI contact to call if the firm receives a fishy order. All sales require a "know your customer" form that requires staff to fill out whether the end user is military or nonmilitary and privately or publically held, and what the end use is. However, the individual added that "we are not the police." Sometimes when this interviewee follows up with a customer to get more due diligence information the person disappears. This happened recently, and if that customer continued to correspond then the interviewee likely would have reached out to the FBI contact.

One interviewee occasionally passed along suspicious requests to government authorities, and told a story about receiving an illicit request from Iran-related entities, which was promptly followed up by a visit from Bureau of Industry and Security, Office of Export Enforcement agents. However, the interviewee merely deletes most of the illegitimate requests, and said that given the onerous nature of government follow-up investigations sometimes it is better not to say anything.

Another interviewee received a foreign quote request for an item that was the exact shape and size used by a weapons facility, but did not quote that job.

An interviewee has worked with U.S. export enforcement at times, but not lately. Often, the firm uses the MK Data Services to fill in the gaps in an application. One issue the interviewee wrestles with is how to screen effectively. The firm has an internal system for export control review, and if there are any questions the interviewee requires an end user statement. Sales must fill out an end use form for international sales. When asked whether there were sales that, after investigation, were too risky to complete, the interviewee said that some prospects disappear after the request for an end use statement, and added that "the ones we say no to are the ones who are linked to SDNs [prohibited parties].” 
Some interviewees described specifics of their firms' internal compliance programs. One said that the firm has taken an extremely aggressive approach over the past year to ensuring that its recent nonproliferation issues are not repeated. The interviewee believes that the majority of diversions occur because brokers have the opportunity to profit, either through negligence or malfeasance.

Under a new initiative, the firm will only ship export-controlled products directly to the end user specified on the export license. While the firm will still accept orders from foreign distributors, it does not allow the distributors to take possession of the items. Further, the firm has implemented strict end-user verification procedures. Any foreign company that purchases more than $\$ 30,000 /$ year of export-controlled items must first be visited by a corporate sales representative. The firm defined this threshold to prevent acquisitions for uranium enrichment applications, while not creating onerous obligations on small buyers. Within 90 days of this initial verification, another sales representative must re-visit the site, and the individual may not come from the same sales region as the first representative. Any change in the shipment's destination requires a new export license, and a new set of verification visits.

The firm pays for the shipping costs themselves, and uses their own shipping agents. The items are sent to a bonded warehouse in the buyer's country, and are only released to the authorized end user at the authorized location. The interviewee noted that this practice has actually improved their supply chain management because they have better awareness of where their items are. The firm plans to re-verify all end users every 3-5 years.

Another interviewee educates the firm's sales managers to beware of diversion and conducts a training event once every two years for all staff, with an additional training event for sales staff every year. The interviewee also performs ongoing audits.

An interviewee said that the firm's goal is to be "nowhere near the line" when it comes to adherence to export regulations. As an example, the interviewee noted that in the late 2000s restrictions on exports to Qaddafi's Libya were beginning to ease. However, the firm chose to take a "more conservative stance" and refrain from selling to Libya. Part of this decision is that the extra compliance assurances outweighed the benefit of additional business. Furthermore, while many firms only require staff to complete online training when they are first hired, the interviewee's firm requires all employees to attend a refresher session in person every other year. The interviewee also mentioned that every invoice has a destination control statement on it to make the customer aware of his or her export control obligations. Another interviewee thought it would be useful for BIS to recommend in the Export Administration Regulations that all firms send a letter to the end user alerting them to the restrictions on the product.

One interviewee personally sits down with each customer when the contract is signed, and always deals directly with the end-user.

An interviewed firm uses Kewill compliance screening software, and screens all foreign nationals that visit the facility. They screen anyone who does not hold a U.S. passport, and staff work with Tom Andrukonis of DOC/BIS/OES when they have licensing questions. An interviewee from the firm also attended BIS seminars.

One firm produces an "export" version of most of its products, which the firm specifically designs to not require a license. The company still runs a background check on each potential customer. The interviewee mentioned that the sophistication and care used in their internal compliance program has been 
developed over the last few years. Repeated Department of Homeland Security (DHS) audits have stimulated some of the firm's improvements, but it is unclear whether these occurred in response to an enforcement action.

An interviewee is not sure proliferation is occurring through unwitting actors. The interviewee noted that BIS's “Don't Let This Happen To You” document is nearly exclusively criminal prosecutions, and perceived that most noncompliance is by witting actors. However, PNNL's analysis of prosecution documents suggests that procurement agents continue to target unwitting actors. 



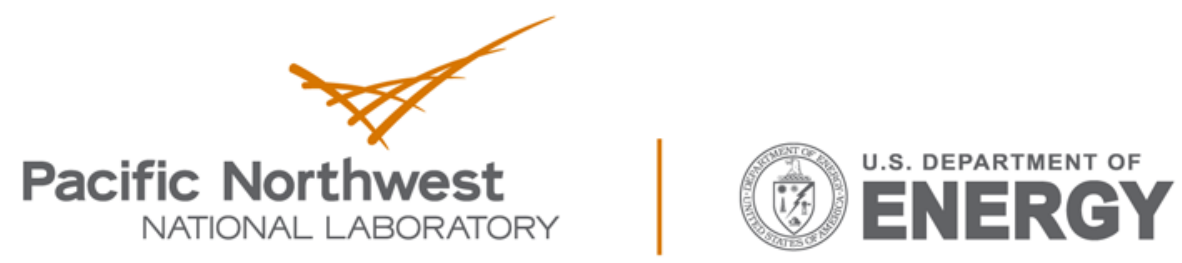

Proudly Operated by Battelle Since 1965

902 Battelle Boulevard

P.O. Box 999

Richland, WA 99352

1-888-375-PNNL (7665)

www.pnnl.gov 